Howard Florey states in the preface, the volume does not cover the whole field of general pathology, though the subjects of each lecture have been carefully selected. The value of the book, however, would have been enhanced if some chapters on neoplastic disease could have been included, and it is hoped that in any future edition this omission may be rectified.

A praiseworthy endeavour has been made to give short historical reviews of each of the subjects discussed. At places the review is too condensed and becomes merely a list of names, meaningless to the average student, as, for example, on p. 23, where Ribbert, Senftleben, Councilman, Marchand, Hohnfeldt and Maximow are all mentioned in a single line, only three of these being referred to elsewhere in the text. It is to be regretted in a book where historical accuracy has been the keynote that the primary lung focus (p. 662) should be referred to as the "Gohn focus" when it was originally described by Parrot forty years before Gohn's treatise on the subject appeared. In a volume where so much attention has been given to detail, it would be easy for any reviewer to find points to criticize. In Fig. 24 on p. 97, the fibrous tissue encapsulating an abscess would be better described as granulation tissue. In the chapters on inflammation of mucous membranes, many pages have been devoted to the secretion of mucus; but the all too common eatarrhal inflammation of the respiratory tract is dismissed in two short paragraphs. The chapter on degenerative changes is disappointing, and the description of amyloid change and the accompanying plates are particularly poor. On the other hand, the lectures on immunological problems are masterly expositions of the subject, as also are those on inflammation.

This is a book which should be read by every serious student of pathology, in particular those working for higher degrees. Many an older pathologist, too, will derive benefit and may have to sacrifice some of his long-cherished ideas about even the simplest pathological phenomena. It is not a book that can be advised for the average student commencing the study of the subject, as the complexities of an already difficult subject are not made any simpler. In these days of overcrowded curricula in medical schools, the student has to acquire his knowledge quickly and easily, and it would be difficult for him to do so from the present volume.

JOHN W. S. BLACKLOCK

\section{SPIDERS OF BRITAIN}

British Spiders

Vol. 2. By G. H. Locket and A. F. Millidge. Pp. vii +449 . (London: Ray Society, 1953.) 30s.

HIS volume completes the survey of the spiders of the British Isles, begun by the authors, G. H. Locket and A. F. Millidge, several years ago, so that now for the first time since John Blackwall's historic folios of 1861-63 (also Ray Society publications) a guide to all the native species is generally accessible. The congratulations which were offered when the first volume was reviewed (Nature, 168, 714; 1951) may here be unhesitatingly repeated.

The arrangement of the descriptive matter follows exactly the plan of the earlier part of the work, and therefore shows the same combination of clearness and conciseness with practical helpfulness that was so conspicuous there. In brief, when the identifying of a species is easy, the authors waste neither time nor space; when it is difficult, fuller treatment and comparative tables come to the reader's aid. The illustrative drawings, which are the work of both, are remarkable for their uniform clarity. They are well reproduced and are, perhaps, one of the outstanding features of the book.

This second volume, which is larger than its predecessor, describes seven families and 369 species. There are, again, illustrations of the genitalia of both sexes of every species, accompanied by such other diagrams and dichotomic keys as are necessary. The distribution of all species is also given-broadly in geographical, and more precisely in ecological, terms.

Among the seven families described are the Agelenidae, which includes the ordinary spiders to be found in dwelling-houses, and the Argiopidae, which are familiar because they spin orb-webs. These pages will interest any reader; but the serious student is likely to turn first to the treatment of the Linyphiidae - the dominant British family of 245 of the smallest spiders in the land. He will find a most impressive key to the one hundred genera by which the family is represented in the British Isles; and although its composer, Dr. Millidge, writes of it with modest reference to its fallibility, it is at the same time true that never before has the captor of a Linyphiid been able to turn to so complete and authoritative a guide as is published here. Only those who have tried to steer a course through the complexities of this family can fully appreciate the nature of Dr. Millidge's very considerable achievement.

Two other points should be mentioned. One is a valuable practical hint-the fact that an obscure epigyne can be made more distinct by soaking the specimen in phenol containing 10 per cent of alcohol. The second is the fact that the book ends with a checklist of the 581 species and subspecies recognized as British. It is interesting to compare this number with the 566 recorded by Dr. W. S. Bristowe as lately as 1939 ; and if it may be added that the authors have in their collections several species even more recently found, it is seen that the day of complete knowledge of the British spider fauna is not yet. It is, in fact, most significant to notice how high is the proportion of species described as 'rare' or 'very rare', or for which but one locality is known, or but a few captures have been reported.

It is permissible to glance at the impression made by the two volumes together and to appraise the work as a whole. It is seen to be a first-rate piece of systematic, descriptive writing, which brings the task of naming a spider within the capacity of any careful naturalist. This is a state of affairs which has never existed in Britain until now; and the beginner, the general naturalist or the ecologist is far less dependent on the personal help of the expert than he was. If this view of the position is correct, then the appearance of this work is an event of great importance.

Yet it would be wrong to regard the publication of the book as the end of a phase in British arachnology. It is rather the beginning of a period in which we may expect a rise in the number of those who take a permanent interest in spiders, and a longoverdue increase in the attention paid them by professional zoologists. There are few animals more worthy of study, and a growth in active arachnology would be the reward, apt and appreciated, which the authors so amply deserve. T. H. SAVORY
T. 